\title{
MUMPS EPIDEMIOLOgY IN THE MID-WEST OF IRELAND 2004-2008: INCREASING DISEASE BURDEN IN THE UNIVERSITY/COLLEGE SETTING
}

\author{
D Whyte (I) F O'Dea $^{1}$, C McDonnell 2 , N H O'Connell ${ }^{2}$, S Callinan ${ }^{1}$, E Brosnan ${ }^{1}$, J Powell ${ }^{2}$, R Monahan ${ }^{2}$, R FitzGerald ${ }^{1}$, M Mannix ${ }^{1}$, \\ T Greally', A Dee ${ }^{1}$, P O'Sullivan ${ }^{1}$ \\ 1. Department of Public Health, Health Service Executive (West), Limerick, Ireland \\ 2. Serology Department, Mid-Western Regional Hospital, Limerick, Ireland
}

\begin{abstract}
Mumps is a contagious vaccine-preventable viral disease that is experiencing a revival in students attending second and third level colleges. Large mumps outbreaks have been reported in several countries despite the presence of childhood immunisation programmes over many years, including measles, mumps, and rubella (MMR) vaccination. In 2008, 1,377 cases of mumps were notified in Ireland and 1,734 in the first three months of 2009 (provisional data). This paper reviews the recent epidemiology of mumps in the Mid-West region of Ireland and highlights preventive measures. A substantial proportion of cases were not laboratoryconfirmed and it is important that doctors continue to notify suspected cases. In the Irish Mid-West, data from enhanced surveillance show a high proportion of mumps in the age group 15-24 years. Complications were uncommon and rarely severe. Where data were available, over half of the cases did not recall having received two doses of MMR, but most recalled one dose. Parents should continue to ensure children receive both MMR vaccinations so that uptake is optimal for protection. Steps were taken to increase awareness of the disease in the school, college and university settings. Preventive measures implemented to limit mumps transmission in the school/college setting over recent years included vaccination of close contacts, isolation for five days and hand hygiene.
\end{abstract}

\section{Introduction}

Mumps (or infectious parotitis) is an acute infection caused by an RNA virus of the family Paramyxoviridae. It is spread directly from infected person to susceptible person by sneezing, droplets and close contact. Mumps can present with mild influenza-like symptoms which may include fever, headache and painful swollen salivary (usually parotid) glands [1]. Complications are usually infrequent but infection can progress to meningitis, deafness as well as orchitis, oophoritis or pancreatitis (inflammation of the testicles, ovaries or pancreas). Mumps infection during pregnancy is not associated with congenital malformations [2]. The incubation period is $16-18$ days (range: $14-25$ days), and recent data suggest an infected person is contagious during the period from two days before to five days after onset of symptoms [3].

Mumps is a vaccine-preventable disease. The measles, mumps and rubella (MMR) vaccine offers safe and effective protection against these diseases and is provided free of charge to children at the age of 12-15 months (MMR1) as part of the Irish Primary Childhood Immunisation Programme (PCIP) [4]. Prior to 1996 , there was no structured PCIP, only recommendations on immunisation. Electronic records of childhood vaccinations in Ireland for national and regional uptake monitoring are only available from 1996. Documentation of MMR status in people born prior to 1996 relies on manual records. Immunisation programmes rely on achieving over $95 \%$ uptake of MMR vaccine to protect the population from disease - especially the most susceptible, children under two years of age. Vaccine uptake in some areas of Ireland has only lately recovered to levels of over $90 \%$ after public confidence in combination vaccines was eroded by published research about possible side effects that has since been rejected [5]. Uptake levels in Ireland for MMR 1 at the age of 24 months averaged below $80 \%$ until 2004 but reached $89 \%$ in 2008 (90\% in the Mid-West) [6].

In 1989, about 700 mumps cases were notified in Ireland, but this number declined to between 30 and 40 cases annually after MMR1 was introduced in 1988. MMR2 (second dose of vaccination) was introduced in 1992 for $11-12$ year-olds. Case numbers rose again in 1996-1997 (300-400) but subsequently fell back to 30-40 annual cases until the year 2002. In line with a recommendation from 1999, the age for MMR2 was brought forward to the age of 4-5 years in 2001. In 2008, 1,377 cases were reported in Ireland, half of whom were laboratory-confirmed. In the context of even higher infection levels observed in Ireland since the beginning of 2009, (a greater than ten-fold increase on 2008), it is timely to review the epidemiology of mumps infection in the Irish Mid-West over the preceding five year period to help explain the factors which may have been of influence.

In recent years a large number of cases of mumps have been reported in young adults, arising from transmission of the virus in so-called 'third level colleges' (colleges/universities attended by students aged 18 years and over), but also in some secondary schools (with 12-18 year-old students). Mumps outbreaks in third level colleges have been reported in Ireland since 2004 [7] and in several other countries [8-11]. This paper reviews the epidemiology of mumps infection in the Mid-West of Ireland from 2004 to 2008 and describes the source, demography of cases, risk factors and the spectrum of illness and examines the role of preventive measures. 
Geographically, the Mid-West of Ireland includes the administrative counties of Clare, Limerick and North Tipperary with a population of 361,028 people. There are three large university/ college institutes in Limerick city and smaller third level colleges in Tipperary including the national Garda (Police) Training College.

\section{Methods}

Suspected or confirmed mumps cases have been subject to mandatory notification in Ireland since 1988 (and outbreaks since 2004) and must be reported to the Medical Officer of Health $(\mathrm{MOH})$ in the Mid-West by medical doctors and laboratories [12]. Notifiers should have regard to Irish case definitions for mumps [13], which is based on the case definition of the European Union, but it adds the classification 'possible case' for clinical cases that are not laboratory-confirmed or are epidemiologically linked to a confirmed case. Where possible, enhanced surveillance data (on complications, symptoms, travel, etc.) were collected by medical officers in the regional public health department. Data on MMR vaccination history were based largely on family or doctor recall rather than on records. A copy of the national enhanced surveillance form for mumps is available online (http://www.ndsc.ie/hpsc/A-Z/ VaccinePreventable/Mumps/SurveillanceForms/) from the Health Protection Surveillance Centre in Dublin. This core dataset is larger

\section{T A B L L}

Mumps cases for whom enhanced surveillance data were available, by notification type, Mid-West of Ireland, 2004-2008 (n=186)

\begin{tabular}{|l|c|c|c|c|}
\hline & \multicolumn{4}{|c|}{ Notification Type (enhanced surveillance) } \\
\hline Year Notified & Clinical & Laboratory and clinical & Laboratory & Total \\
\hline 2004 & 4 & 0 & 1 & 5 \\
\hline 2005 & 57 & 3 & 12 & 72 \\
\hline 2006 & 8 & 0 & 3 & 11 \\
\hline 2007 & 4 & 0 & 1 & 5 \\
\hline 2008 & 43 & 17 & 33 & 93 \\
\hline $2004-2008$ & $116(62 \%)$ & $20(11 \%)$ & $50(27 \%)$ & $186(100 \%)$ \\
\hline
\end{tabular}

and more disease-specific than the minimal dataset required under legislation for the generic list of notifiable diseases.

Data on clinical notifications from general practitioners and hospital doctors were collated by the Department of Public Health where notifications to the $\mathrm{MOH}$ are recorded. Laboratory data notified from the Department of Serology, Mid-Western Regional Hospital, Limerick and the National Virus Reference Laboratory (UCD) were collated. Laboratory notified cases were confirmed by the detection of mumps specific IgM immunoglobulin in serum or oral fluid specimens. The test is an IgM class capture enzyme immunoassay (MACEIA, Microimmune Ltd., United Kingdom). The reported sensitivity and specificity of the assay for serum samples is $94.7 \%$ and $95.9 \%$, respectively, when compared to IgM antibody capture radioimmunoassay (MACRIA). For oral fluid samples, the sensitivity and specificity compared to MACRIA is $92.6 \%$ and $100 \%$, respectively. Data were collected, entered into secure databases and analysed in MS Excel and SPSS. Analysis by age, sex, symptoms, complications and vaccination history was confined to the enhanced surveillance dataset.

\section{Results}

From 1 January 2004 to 31 December 2008, 319 mumps notifications were received by the Mid-West $\mathrm{MOH}$. Three records were removed as duplicates and 14 were re-classified as denotified as laboratory data became available, leaving 302 records. Over the five year period, 109 laboratory-confirmed notifications (36\%) and 193 clinical notifications (64\%) were recorded. Enhanced surveillance was completed for 186 mumps cases (71\% of 262 notified cases); 116 of them were clinical notifications only, 50 were laboratory confirmed only, and 20 were notified clinically and laboratory-confirmed (see Table 1).

Figure 1 shows all notified mumps cases, inclusive of those cases for whom enhanced surveillance information was available. With the exception of the academic year 2006-7, the number of mumps cases was relatively low in summer, and peaked in autumn in the months after third level colleges resume (Figure 1). An intervention with MMR vaccination was carried out by public

F I G U R E 1

Mumps cases with enhanced surveillance data and other mumps notifications, by year and month, Mid-West of Ireland, 2004$2008(n=263)$

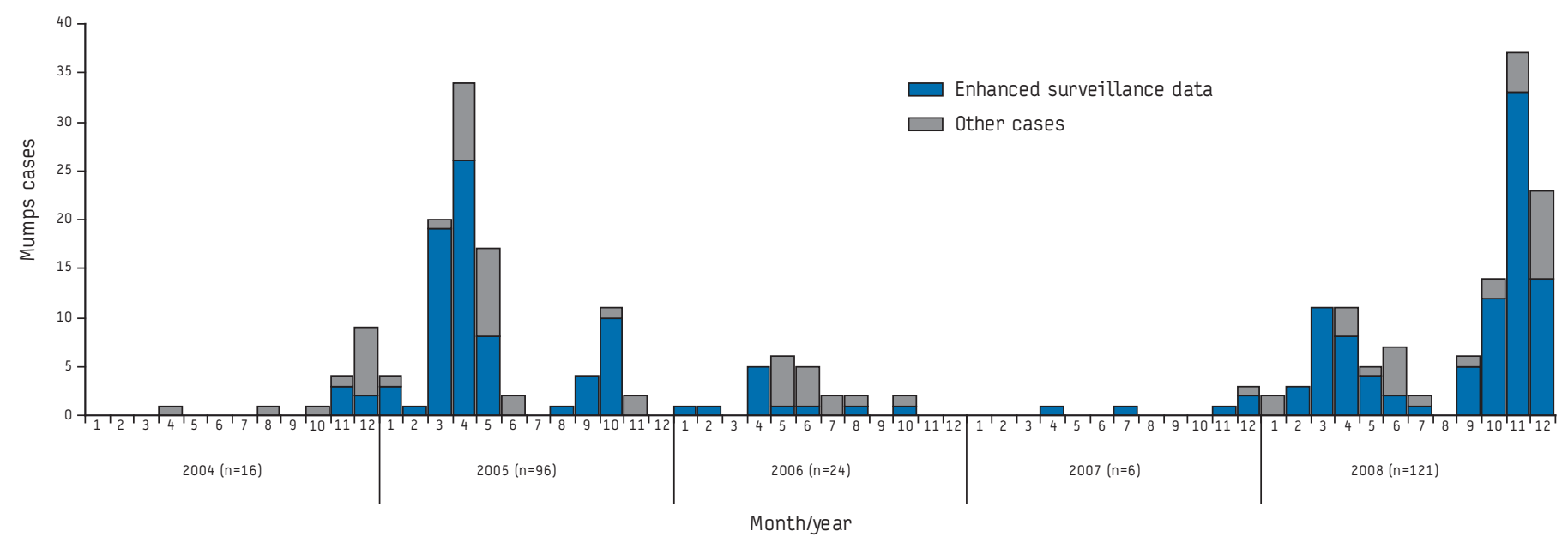


health/university student health services in one large university following a peak in mumps infections in April 2005. This could be an explanation for the change in pattern in 2006-7.

The age range of mumps cases was 1.4 years to 79 years (average 22.9 years, median 20.4 years). There was a slight preponderance of cases in males over females in all years except 2007 (data not shown): from 2004 to 2008, the male:female ratio was $1.4: 1$. For the period from 2004 to 2008 , Figure 2 illustrates the age distribution of mumps cases by sex in the Mid-West. Of 186 cases, 123 were in the age group of $15-24$ year-olds (66\%). This distribution reflects the ongoing transmission since 2004 of mumps virus in susceptible people attending third level colleges in Ireland.

\section{F I G U R E 2}

Age distribution of mumps cases for whom enhanced surveillance data were available, by sex, Mid-West of Ireland, 2004-2008 $\left(n=183^{*}\right)$

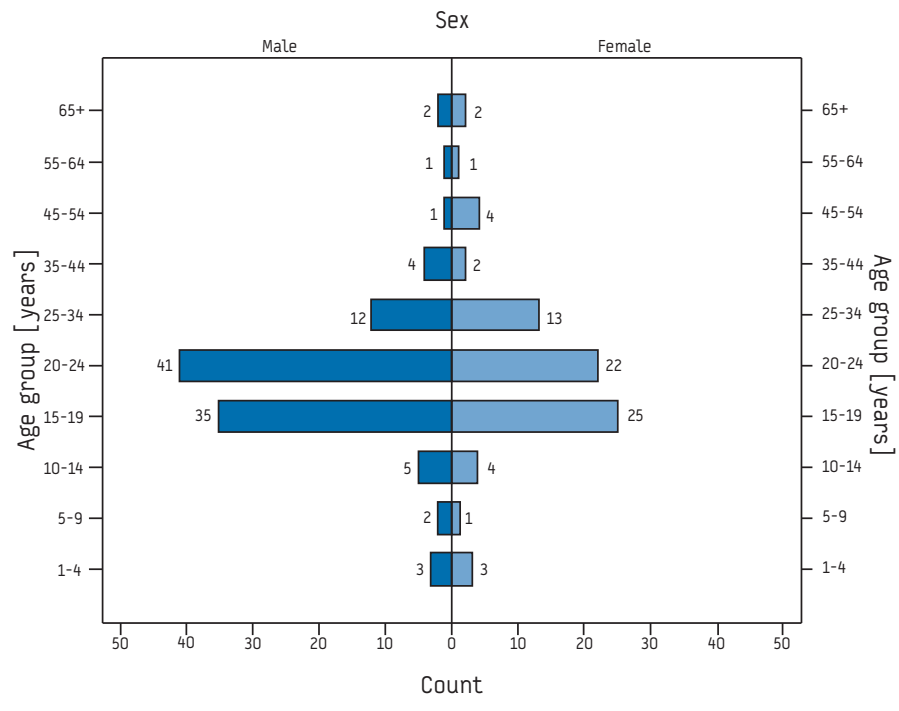

For 186 cases over the five year period, symptoms and complications are shown by sex in Table 2. Nausea, earache, headache and vomiting were mentioned by seven cases as symptoms or complications. Complications of mumps disease were uncommon in female patients (1/78) while $13 \%$ of the male cases (14/108) reported complications. Seven cases (four male and three female) were hospitalised, 5\% of the 144 cases for whom such information was available. The outcome 'recovered' was stated for $28 \%$ of cases $(52 / 186)$. No deaths were reported.

Investigation of the cases to determine the likely place of acquisition of mumps infection implicated several settings but university/college and secondary schools were reported in 54 cases ( $71 \%$ of 75 cases for whom this information was acquired), four in secondary schools and three in primary schools. The University of Limerick, a campus-style third level college, was associated with the vast majority of the infections acquired in university/college and with some related cases. Two mumps outbreaks were reported from the Mid-West - one in the community and one mixed community/ college event.

Twelve cases ( $8 \%$ of cases where data were given) occurred in foreign-born nationals. Travel (25 days before onset) was reported in 16 cases, but only four had travelled "overseas" (two to the United Kingdom, one to North America and one to Africa). One case was reported as acquired overseas. Travel within Ireland appeared consistent with students commuting to their home counties.

Data on childhood MMR vaccination were ascertained for a large proportion of these mumps cases (78\%; 146/186) and are shown in Table 3. MMR vaccination was not evident in the older cases (over 25 years of age), which is not unexpected. Where data were provided in young adults (15-24 years), $7 \%$ of cases (7/103) reported not receiving any $\mathrm{MMR}, 49 \%(51 / 103)$ had at least one MMR (MMR1) and 44\% (45/103) reported receiving two doses (MMR2).

\section{Discussion}

Historically, in the Irish setting, mumps occurred in children between the ages of five and 15 years, although the disease

*Age for three of the 186 cases unknown.

T A B L E 2

Mumps cases with enhanced surveillance data showing symptoms and complications, by sex, Mid-West of Ireland, 2004-2008 (n=186)

\begin{tabular}{|c|c|c|c|c|c|c|}
\hline \multirow[b]{2}{*}{ Symptoms } & \multicolumn{3}{|c|}{ Males ( $n=108$ ) } & \multicolumn{3}{|c|}{ Females ( $n=78$ ) } \\
\hline & Yes & No & Not given/unknown & Yes & No & Not given/unknown \\
\hline Parotitis swelling & $98(91 \%)$ & 3 & 7 & $69(88 \%)$ & 5 & 4 \\
\hline Bilateral parotitis & $46(43 \%)$ & 49 & 13 & $26(33 \%)$ & 43 & 9 \\
\hline Fever & $53(49 \%)$ & 41 & 14 & $20(26 \%)$ & 44 & 14 \\
\hline \multicolumn{7}{|l|}{ Complications } \\
\hline Meningitis & $1(1 \%)$ & 95 & 12 & 0 & 69 & 9 \\
\hline Encephalitis & $1(1 \%)$ & 94 & 13 & 0 & 69 & 9 \\
\hline Orchitis/Oophoritis & $12(11 \%)$ & 82 & 14 & 0 & 69 & 9 \\
\hline Deafness & 0 & 95 & 13 & 0 & 69 & 9 \\
\hline Mastitis & 0 & 94 & 14 & 0 & 68 & 10 \\
\hline Pancreatitis & $1(1 \%)$ & 94 & 13 & $1(1 \%)$ & 69 & 8 \\
\hline
\end{tabular}

Due to the small numbers, we did not undertake a statistical analysis. 
was also seen in adults. The current epidemiological picture of mumps in the Mid-West of Ireland is an ongoing upsurge of cases in third level colleges and the wider community. Transmission of mumps virus in college students occurs in classroom, residential settings and social or sports activities, and contacts may require public health follow-up over a large geographic area. ProMED mail reported, in April 2009, that two third level college students in the United States (US), both having had two doses of mumps vaccine, have suspected mumps after returning from Ireland. US public health authorities think further cases are likely [14].

In many students mumps was probably prevented by MMR vaccination, and the immunity conferred probably limited outbreaks in the community. Nevertheless, mumps outbreaks are continuing in third level colleges. Slightly more males than females are affected but this may reflect attendance patterns to third level colleges. While complications were more commonly reported in males, a similar proportion of males and females were hospitalised. Students ill with mumps and absent from lectures/studies may experience negative effects on academic progress.

Since 2004, public health authorities maintained ongoing contact with all Mid-West third level college authorities and student health services to promote mumps and MMR awareness in students and staff. College services sent email alerts to the students where possible. Clear information in the college setting is essential for foreign-born students from countries that may not have MMR vaccination. Letters were issued to general practitioners and hospital doctors advising them of the upsurge in cases and reminding them of the requirement to notify mumps cases. Cases were advised to stay off work/college for five days after the onset of symptoms. Vaccination of close contacts, isolation and hand hygiene were promoted as key measures to prevent further disease transmission. The national outbreak control team, convened in 2004 in Ireland, recommended that new third level students under the age of 25

\section{T A B L E 3}

Mumps cases with enhanced surveillance by age group and measles, mumps, rubella (MMR) vaccination, Mid-West of Ireland, 2004$2008(n=186)$

\begin{tabular}{|l|c|c|c|c|c|}
\hline & \multicolumn{5}{|c|}{ MMR vaccination } \\
\hline Age group (years) & MMR1 & MMR2 & None & Data not given & All \\
\hline $1-4$ & 5 & 0 & 1 & 0 & 6 \\
\hline $5-9$ & 2 & 0 & 1 & 0 & 3 \\
\hline $10-14$ & 5 & 3 & 1 & 0 & 9 \\
\hline $15-19$ & 21 & 23 & 4 & 12 & 60 \\
\hline $20-24$ & 30 & 22 & 3 & 8 & 63 \\
\hline $25-34$ & 6 & 2 & 4 & 13 & 25 \\
\hline $35-44$ & 0 & 0 & 4 & 2 & 6 \\
\hline $45-54$ & 0 & 0 & 2 & 3 & 5 \\
\hline $55-64$ & 0 & 0 & 2 & 0 & 2 \\
\hline$>65$ & 0 & 0 & 2 & 2 & 4 \\
\hline Not given & 0 & 2 & 1 & 0 & 3 \\
\hline Total & $69(37 \%)$ & $52(28 \%)$ & $25(13 \%)$ & $40(22 \%)$ & 186 \\
\hline
\end{tabular}

MMR1: reported receiving one dose of MMR vaccine; MMR2: reported receiving two doses of MMR vaccine. years and attending college during the academic years 2005-6 to 2007-8, who had not already had two doses of MMR should have one dose of MMR vaccine [7]. Advisory measures, unless supported by specific, ring-fenced resources, may be considered too passive as interventions to control continued mumps transmission. A strategic, national, targeted immunisation campaign in third level colleges was not undertaken in Ireland, but some regional public health departments did implement some active outbreak management measures in institutions. In March and April 2005, an outbreak was declared by the $\mathrm{MOH}$ in the largest third level college in the MidWest, which resulted in an active targeted vaccination campaign involving several thousand students and staff. This may have had an impact by increasing herd immunity for that cohort of students and reduced mumps transmission in this institution in the subsequent years, 2006 and 2007.

People who received only one MMR dose may not be protected against mumps. The level of protection against mumps given in different reports varies from $65 \%$ to $90 \%$ after one dose [11]. Cases of mumps in people who reported receiving two MMR doses may indicate a combination of primary and secondary vaccine failure [15]: Immunity may wane after a number of years [16], owing to the comparatively low immunogenicity of the mumps component of MMR $[8,17]$, There may be a genotype mismatch between circulating wildtype virus and the vaccine virus [18]; Lastly, true vaccine failure may be responsible. Several reasons could explain uncommon primary vaccine failure (e.g. incorrect storage, transport), and some have implications for the protective effect of the other two components of the vaccine. Nevertheless, parents should continue to have their child vaccinated with MMR according to national immunisation recommendations.

DiRenzi et al. reported in 2004 using ESEN2 data that approximately $80-85 \%$ of individuals in Ireland aged between 15 and 24 years were immune to mumps and that this relatively low level of immunity may be a reflection of the impact of MMR vaccination and subsequent decrease in exposure to wild mumps virus circulation [19]. It is likely that a proportion of susceptible individuals from this cohort will be attending secondary schools and higher education colleges between now and 2013. More individuals who are susceptible to mumps may arise from a global shortage of MMR that occurred in 1994 during which MR (measles, rubella vaccine) was used instead, as preventing a measles epidemic was a priority [20].

Our analysis underlines some particular issues in mumps surveillance in Ireland. Missing data was a limiting factor in the analysis of the mumps enhanced surveillance dataset and illustrates the competing objectives in public health infectious disease surveillance. In crisis situations such as an outbreak priorities are shifted to outbreak management and clinical follow-up at the expense of timely and complete surveillance. Analysis was confined to mumps notifications where enhanced surveillance was undertaken, hence the representativeness of this sample may be prone to some bias. Accuracy and objectivity of MMR vaccination status is open to question where the classification depended on recall rather than records.

Traditional epidemiological measures, like mumps incidence, are difficult to interpret as geography and census data do not provide a clear denominator for these cases in this setting due to the mobile cohort of students commuting to colleges in the Mid-West from neighbouring counties. Validating mumps notifications nationally to 
avoid duplication and overestimation remains a challenge, although the full implementation of a national computerised infectious disease reporting system (CIDR) may improve surveillance in future. Public health relies greatly on general practitioners and hospital clinicians notifying cases. More cases of mumps are reported clinically than are confirmed and notified by the laboratories. While mumps may have some classical symptoms and signs on presentation, clinicians may confirm cases by either serum IgM serology or by non-invasive salivary IgM testing. However, testing at the appropriate time in the clinical course of disease is important consideration in order to avoid apparently conflicting results $[21,22]$.

A national outbreak control team was re-convened in 2009 and has recommended re-enforcing the present measures and adopting further active interventions, regionally and nationally, to control future transmission of mumps at secondary schools and third level colleges in Ireland.

\section{Aknowledgements}

The patience and assistance of all the staff in the Health Protection Surveillance Centre is acknowledged. The Department of Public Health is appreciative of all notifications, especially mumps, from general practitioners and hospital clinicians. The work of the doctors and nurses and administrative staff in the colleges of the Mid-West is also acknowledged. Special thanks to Ms Orla Hanrahan, Surveillance Officer, and Ms Ann Sweeney and Ms Breda Tuohy, Surveillance Assistants, for diligent and timely data input in the Department of Public Health.

\section{References}

1. Falk WA, Buchan K, Dow M, Garson JZ, Hill E, Nosal M, et al. The epidemiology of mumps in Southern Alberta 1980-1982. Am J Epidemiol. 1989;130(4):736-49.

2. Siegel M. Congenital malformations following chickenpox, measles, mumps, and hepatitis. Results of a cohort study. JAMA. 1973;226(13):1521-4.

3. Polgreen PM, Bohnett LC, Cavanaugh JE, Gingerich SB, Desjardin LE, Harris ML, et al. The duration of mumps virus shedding after the onset of symptoms. Clin Infect Dis. 2008;46(9):1447-9.

4. Health Service Executive (HSE). National Immunisation Office. Protect Health - Immunise (Website on the internet). [Accessed April 2009]. Available from: http://www.immunisation.ie

5. Andreae MC, Freed GL and Katz SL. Safety concerns regarding combination vaccines. Perspective of select European countries. Hum Vaccin. 2005;1(1):1-5.

6. Health Service Executive (HSE). Health Protection Surveillance Centre. Summary Immunisation Uptake Statistics. Dublin: HSE. 2009. Available from: http://www.hpsc.ie/hpsc/AZ/VaccinePreventable/Vaccination/ ImmunisationUptakeStatistics/ImmunisationUptakeStatisticsSummary/ File,954,en.pdf (Last accessed April 2009)

7. Gee S, O'Flanagan D, Fitzgerald M, Cotter S. Mumps in Ireland, 2004-2008. Euro Surveill. 2008;13(18):pii=18857. Available from: http://www.eurosurveillance. org/ViewArticle.aspx?ArticleId=18857 (Last accessed April 2009)

8. Conly J, Johnston B. Is mumps making a comeback? Can J Infect Dis Med Microbiol. 2007; 18(1):7-9.

9. Centers for Disease Control and Prevention (CDC). Mumps epidemic-Iowa, 2006 MMWR Morb Mortal Wkly Rep. 2006; 55(13):366-8.

10. Cortese MM, Jordan HT, Curns AT, Quinlan PA, Ens KA, Denning PM, et al. Mumps vaccine performance among university students during a mumps outbreak. Clin Infect Dis. 2008;46(8):1172-80.

11. Savage E, Ramsay M, White J, Beard S, Lawson H, Hunjan R, et al. Mumps outbreaks across England and Wales in 2004: observational study. Brit Med J. 2005; 330(7500): 1119-20.

12. Government of Ireland. Infectious Diseases (Amendment) Regulations, 1988. Statutory Instrument S.I. No. 288 of 1988. Available from: http://www. irishstatutebook.ie/1988/en/si/0288.html (Last accessed April 2009)

13. Health Protection Surveillance Centre. Case Definition for Notifiable Diseases 2004. Available from: http://www.ndsc.ie/hpsc/A-Z/VaccinePreventable/Mumps/ CaseDefinitions/File,2850,en.pdf (Last accessed April 2009)
14. ProMED-mail. Mumps - USA: (Massachusetts) ex Ireland. Archive Number 20090417.1455. 17 April 2009. Available from: http://www.promedmail.org/pls/ otn/fp=2400:1001:4405464973023774::N0::F2400_P1001_BACK_PAGE,F2400_P1001 PUB_MAIL_ID:1010,77078

15. Vandermeulen C, Roelants M, Vermoere M, Roseeuw K, Goubau P, Hoppenbrouwers $K$. Outbreak of mumps in a vaccinated child population: a question of vaccine failure? Vaccine. 2004;22(21-22): 2713-6.

16. Cohen C, White JM, Savage EJ, Glynn JR, Choi Y, Andrews N, et al. Vaccine effectiveness estimates, 2004-2005 mumps outbreak, England. Emerg Infect Dis. 2007;13(1):12-7.

17. Harling R, White JM, Ramsay ME, Macsween KF, van den Bosch C. The effectiveness of the mumps component of the MMR vaccine: A case control study. Vaccine. 2005;23(31): 4070-4.

18. Kaaijk P, van der Zeijst BA, Boog MC and Hoitink CW. Increased mumps incidence in the Netherlands: Review on the possible role of vaccine strain and genotype . Euro Surveill. 2008;13(26):pij=18914. Available from: http:// www.eurosurveillance.org/ViewArticle.aspx?ArticleId=18914 (Last accessed April 2009)

19. Di Renzi M, Jackson S, Gee S, Cotter S. Increase in mumps in Ireland in late 2004. Euro Surveill. 2004:8(52):pii=2608. Available from: http://www. eurosurveillance.org/ViewArticle. aspx?ArticleId=2608 (Last accessed April 2009)

20. Centers for Disease Control and Prevention (CDC). Mumps epidemic - United kingdom, 2004-2005. MMWR Morb Mortal Wkly Rep. 2006; 55(7):173-5.

21. Reid F, Hassan J, Irwin F, Waters A, Hall W, Connell J. Epidemiologic and diagnostic evaluation of a recent mumps outbreak using oral fluid samples. J Clin Virol. 2008;41(2):134-7.

22. Cunningham C, Faherty C, Cormican M, Murphy AW. Importance of clinical features in diagnosis of mumps during a community outbreak. Ir Med $\mathrm{J}$. 2006;99(6):171-3.

This article was published on 23 April 2009.

Citation style for this article: Whyte D, O'Dea F, McDonnell C, O'Connell NH, Callinan S, Brosnan E, Powell J, Monahan R, FitzGerald R, Mannix M, Greally T, Dee A, O’Sullivan P. Mumps epidemiology in the Mid-West of Ireland 2004-2008: increasing disease burden in the university/college setting. Euro Surveill. 2009;14(16):pii=19182. Available online: http://www.eurosurveillance.org/ViewArticle.aspx?ArticleId=19182 